\title{
Esophageal foreign body removal using endoscopy in cat
}

\author{
Sitaria F. Siallagan ${ }^{1, *}$, Herawati Napitu ${ }^{2}$, Arni D. Fitri ${ }^{1}$, Nindya D. Utami ${ }^{1}$, \\ Soenarti D. Waspada ${ }^{2}$, Deni Noviana ${ }^{1,3}$ \\ ${ }^{1}$ Veterinary Teaching Hospital, Faculty of Veterinary Medicine, Bogor Agricultural University, Bogor, Indonesia \\ ${ }^{2}$ DNA Animal Clinic, Bogor, Indonesia \\ ${ }^{3}$ Department of Clinic, Reproduction, and Pathology, Faculty of Veterinary Medicine, Bogor Agricultural University \\ Bogor, Indonesia
}

\begin{abstract}
A 10-months-old cross long hair cat named Casper with clinical symptom of vomiting mixed with slimy cat feed was referred to Veterinary Teaching Hospital, Faculty of Veterinary Medicine, Bogor Agricultural University to endoscopy examination and therapy. The owner believed that Casper ate a $5 \mathrm{~cm}$ long sewing needle a few days earlier. The history and physical examination were examined at DNA Clinic with symptoms of lack of appetite and becoming quieter and calmer. Radiogram showed the needle was in thorax area with a vertical needle penetrating the esophageal wall. Removal of the needle and observation of the esophagus area were done using endoscopy under general anesthesia. Using endoscopy, it was known that the needle was swallowed along with the sewing thread with position of all needles penetrating the esophagus wall and leaving a small amount of thread on the lumen. The needle was pulled back to the esophageal lumen by pulling the remaining thread and then both needle and the thread were pulled back out using an alligator grasping forceps that used through working channel. Therapy given after endoscopy was antibiotics and anti-emetics.
\end{abstract}

Keywords:

Cat, endoscopy, needle, foreign object

\section{- INTRODUCTION}

Ingestion of foreign bodies is a serious problem for animals. Ingestion foreign body is a common case in human (Karadas et al. 2016) and small animal (Prat et al. 2014). The most frequently ingested foreign bodies in pet animals are magnets, latex teats, wood foreign bodies, such as skewers or ice pop sticks, corn cobs, pet toys, children's toys, and solidified wood glue, sewing needles (Prat et al. 2014; Cornell \& Koenig 2015). Once foreign body ingestion is diagnosed, the physician must decide whether the treatment is necessary according to the emergency of the case.

\section{- CASE}

Casper, a 10-months-old cross long hair cat, was examined in DNA animal clinic because the owner believed that Casper ate a $5 \mathrm{~cm}$ long sewing needle a few days earlier. The radiogram showed the needle was in thorax area with a vertical needle penetrating the esophageal wall (Fig. 1A). Casper was then injected non steroid anti-inflammatory drug (Metacam ${ }^{\circledR}$ Boehringer Ingelheim Vetmedica) and antivomit (Cerenia ${ }^{\circledR}$ Zoetis US). Three days later, Casper back to the clinic with clinical symptoms of vomiting mixed with slimy cat feed. Casper was quieter and calmer than before. Due to the position of the needle still in the initial position, Casper was referred to Veterinary Teaching Hospital, Faculty of Veterinary Medicine, IPB University (RSHP FKH IPB) to endoscopy examination.

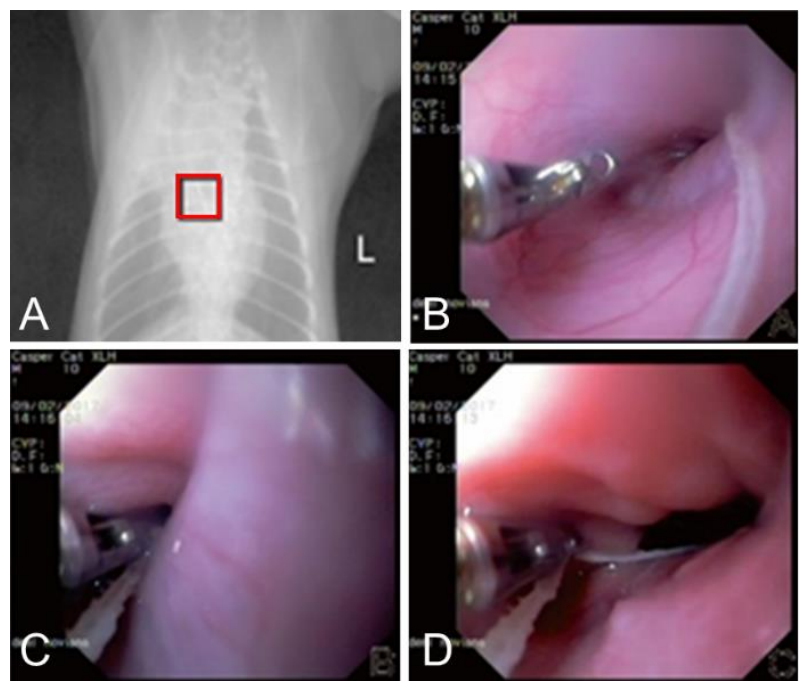

Figure 1. Radiogram and esophageal needle and thread removal using endoscopy. (A) ventro-dorsal view. red square: the needle, (B) endoscope's tip approached the thread, (C) endoscope's tip pinched the thread, (D) Endoscope's tip pulled out the thread using an alligator grasping forceps that used through working channel.

Before endoscopy procedures were performed, Casper was preanesthesized using dexmedetomidine $(2 \mu \mathrm{g} / \mathrm{kg} \mathrm{BW})$,

Received: 30-01-2020 | Revised: 28-02-2020 | Accepted: 10-03-2020

(C) 2020 CC-BY-SA. This is an Open Access article that is distributed under the terms of Creative Commons Attribution ShareAlike 4.0 International License (https://creativecommons.org/licenses/by-sa/4.0/). 
anesthesized using ketamine (2 $\mathrm{mg} / \mathrm{kg} \quad \mathrm{BW})$ and maintenanced using propofol (4 $\mathrm{mg} / \mathrm{kg} \quad \mathrm{BW})$. Post endoscopy procedure, Casper was treated using amoxicilin LA as antibiotic and maropitan as antiemetic.

Endoscopy examination was performed using $0.8 \mathrm{~cm}$ diameter of endoscope which inserted through the mouth to examine the esophagus and then are displayed on a monitor (Fig. 1B-D). On the monitor, It was seen that the needle was swallowed along with the sewing thread with position of all needles penetrating the esophagus wall and leaving a small amount of thread on the lumen. Using alligator grasping forceps that used through working channel, the needle was pulled back to the esophageal lumen by pulling the remaining thread and then both needle and the thread were pulled back out.

\section{- RESULTS AND DISCUSSION}

Foreign body ingestion is a common reason for emergency visits in small animal practice. Various treatment to remove the foreign body depend on the shape and size of the foreign body, the risk of gastrointestinal obstruction or perforation. The treatment may include intensive monitoring, induction of emesis, and endoscopic or surgical removal (Pratt et al. 2014). According to the radiogram, position of the sewing needle was in thorax cavity, that have a high risk to do a surgery. Therefore, endoscopy had a better possibility to treat and to observe the condition of the oesophagus.

Flexible endoscopy is a minimally invasive procedure in the diagnostic work-up with gastrointestinal sign to examine digestive tract. During an upper endoscopy, an endoscope is easily passed through the mouth and throat into the esophagus (Neiger et al. 2013). It is considered a minimally invasive diagnostic tool, but endoscopic procedures in cat should under general anesthesia to minimize the post procedure complication (Weil 2009).

During the procedure, the needle has penetrated from oesophagus into thorax cavity near of the heart. Fortunately the needle did not penetrate or injure the heart. Although sharp-pointed object should be removed within 24 hours due to the risk of complication (Birk et al. 2016), but on the monitor also seen the esophageal wall was still smooth, thin and there was no esophageal ulcer indicating the needle and threads still induced minimal inflammatory response (Han 2003).

Possible complication include local injury to the mucosa such as abrasion, laceration, necrosis, and stricture formation (Han 2003). Due to the needle left puncture wound mark that could induce inflammation and bacterial proliferation, therefore, after neddle and thread removal, Casper was treated using amoxicilin LA as antibiotic to prevent secondary infection, and maropitan as antiemetic to treat or prevent vomiting caused by needle penetration injury.

\section{- CONCLUSION}

As one of a reason to emergency visit, foreign body ingestion should be treated appropriately. The longer of foreign body presence in the body will induce higher rate of complication. Esophageal foreign body of Casper had been treated appropriately using combination of non-invasive procedure treatment and medicine treatment.

\section{- AUTHOR INFORMATION}

\section{Corresponding Author}

*SFS: sitaria.siallagan@gmail.com

Veterinary Teaching Hospital, Faculty of Veterinary Medicine, IPB University, Bogor, Indonesia

\section{- REFERENCES}

Birk M, Bauerfeind P, Deprez PH, Häfner M, Hartmann D, Hassan C, Hucl T, Lesur G, Aabakken L, Meining A. 2016. Removal of foreign bodies in the upper gastrointestinal tract in adults: European Society of Gastrointestinal Endoscopy (ESGE) Clinical Guideline. Endoscopy. 48(05):489-496.

Cornell K, Koenig A. 2015. Gastrointestinal Foreign Body. Chapter 4. In Small Animal Surgery Emergencies. 1st edition. Pp 33-42.

Han E. 2003. Diagnosis and management of reflux esophagitis. Clinical techniques in small animal practice. 18(4):231-238.

Karadas S, Cegin MB, Sayir F, Gonullu H, Olmez S. 2016. Oesophagus obstruction due to ingestion of multiple foreign bodies. JPMA. The Journal of the Pakistan Medical Association. 66(4):473474.

Neiger R, Robertson E, Stengel C. 2013. Gastrointestinal endoscopy in the cat: diagnostics and therapeutics. Journal of feline medicine and surgery. 15(11):993-1005.

Pratt CL, Reineke EL, Drobatz KJ. 2014. Sewing needle foreign body ingestion in dogs and cats: 65 cases (2000-2012). Journal of the American Veterinary Medical Association. 245(3):302-308.

Weil AB. 2009. Anesthesia for endoscopy in small animals. Veterinary Clinics of North America: Small Animal Practice. 39(5):839-848. 